\title{
PERCEPÇÃO AMBIENTAL DE ESTUDANTES DA ZONA RURAL SOBRE A RESERVA BIOLÓGICA DE SANTA ISABEL, PIRAMBU (SE)
}

\author{
Natali Oliveira Santos Eckert ${ }^{1}$ \\ Lumara Souza Alves Bonfim ${ }^{2}$ \\ Ruany Tacielly Santos Santana ${ }^{3}$ \\ Felipe Alan Souza Santos 4 \\ Paulo Jardel Braz Faiad ${ }^{5}$ \\ Andressa Sales Coelho ${ }^{6}$
}

Resumo: A percepção infantil sobre o meio ambiente tem sido objeto de diversas investigações que visam dar suporte às propostas de Educação Ambiental. O objetivo do presente estudo foi trabalhar o conceito de reserva biológica e sua importância para a conservação da natureza. Foram realizadas: aula de campo, palestra, apresentação de vídeo e atividades práticas em duas escolas municipais de Pirambu (SE), localizadas no entorno da Reserva Biológica de Santa Isabel. A metodologia utilizada seguiu o proposto por Barros et al. (2015). Observou-se que os estudantes têm conhecimento das problemáticas ambientais locais e existem afeição e zelo pelo meio ambiente circundante, no qual eles estão inseridos.

Palavras-chave: Educação Ambiental; Escola; Fauna; Flora; Desenho.

\footnotetext{
1 Universidade Tiradentes, Aracaju, SE. E-mail: natalieckert_mma@hotmail.com

2 Universidade Tiradentes, Aracaju, SE. E-mail: Lumarah_brunelly@hotmail.com

3 Universidade Tiradentes, Aracaju, SE. E-mail: ruanytacielly@hotmail.com

4 Universidade Federal de Sergipe, Aracaju, SE. E-mail: felipesantosprof@hotmail.com

5 Instituto Chico Mendes de Conservação da biodiversidade (ICMBio). E-mail: paulo.faiad@icmbio.gov.br

6 Universidade Tiradentes, Aracaju, SE. E-mail: andscoelho@yahoo.com.br
} 


\section{Introdução}

O termo "percepção" é definido, em grande parte dos dicionários da Língua Portuguesa, como combinação dos sentidos no reconhecimento de um objeto; ato ou efeito de perceber; recepção de um estímulo; representação intelectual; faculdade de conhecer independentemente dos sentidos. Há uma amplitude de possíveis significados a partir desses conceitos, que vão desde a recepção de estímulos até a intuição, a ideia e a imagem, que são categorias diversas no discurso filosófico (MARIN, 2008).

A Educação Ambiental é um processo dinâmico, criativo e permanente, que possibilita a sociedade adquirir conhecimentos, valores e habilidades para ter uma visão crítica e consciente do seu meio ambiente, tornando os cidadãos mais participativos, transformadores e engajados em novas atitudes, na busca pela resolução dos problemas ambientais presentes e futuros (DIAS, 2004). Entretanto, para que a Educação Ambiental seja efetiva, torna-se imprescindível um levantamento das diversas formas de percepção do ambiente no qual os indivíduos estão inseridos, a fim de se compreenderem a visão e a relação que cada um tem com o seu espaço (MARCATTO, 2007; BEZERRA; FELICIANO; ALVES, 2008).

A percepção infantil sobre o meio ambiente tem sido objeto de diversas investigações que visam dar suporte às propostas de Educação Ambiental. E a maioria das pesquisas utiliza o desenho como ferramenta para a compreensão das percepções de crianças sobre o ambiente natural. Os estudos apontam que, à medida que a criança percebe mais o ambiente, ela envolve-se com ele, torna-se capaz de explorá-lo progressivamente e assimila melhor os variados níveis de complexidade que compõem a paisagem (CHAWLA, 2002; KAHN, 2002; TUAN, 1978).

A criança cria, desenha e age de maneira flexível, às vezes artificialmente caótica, mas o faz com necessidade do seu próprio crescimento. $O$ desenho é um pensamento visual, moldando-se a natureza do conhecimento artístico, científico ou funcional. É uma forma de criar hipóteses, explicações e teorias para compreender a realidade, desenvolvendo capacidades projetiva e intelectiva ao expressar graficamente o que pensa. $O$ desenho também pode ser definido como um trabalho lúdico, que envolve elementos imaginários (pensar e projetar) e operacionais (funcionamento temporal, físico e espacial) (DERDYK, 2010).

Além disso, os desenhos permitem um diagnóstico da visão do investigado sobre um fenômeno específico ou temático e sua produção desperta a reformulação de objetos e conceitos. Outras pesquisas envolvendo crianças e ambientes naturais mostram que as crianças se atentam com o meio ambiente nos planos cognitivo, emocional e ético. Assim, quando comparadas com os adultos, as crianças são consideradas mais sensíveis quanto aos problemas ambientais e às relações socioambientais (SNADDON; TURNER; FOSTER, 2008). 
A utilização de desenho para a análise da percepção ambiental infantil sobre a natureza parte da ideia de que, à medida que a criança se desenvolve, a sua percepção é ampliada e os amadurecimentos cognitivo, físico e psicológico proporcionam uma compreensão mais complexa e ampla do ambiente local. Vale destacar que os aspectos culturais e históricos vivenciados como experiências individuais têm grande influência na percepção infantil sobre os ambientes naturais e seus aspectos (BOSSCHE, 2006; SINNER, 2008).

A partir desse envolvimento, a criança organiza e estrutura suas experiências ao traçar soluções para os problemas envolvidos com o objeto. Após ajustar informações referentes a esse objeto, a criança reconstrói a representação, a simbolização e o pensamento; caso não houvesse reconstrução, não haveria níveis de desenho. Logo, o desenho é o registro daquilo que de fato é significativo para a criança, formado pela sua primeira linguagem gráfica na comunicação dos pensamentos, na construção do conhecimento e na comunicação de experiências, que se concretiza com a interação com o objeto (PILLAR, 1996).

Portanto, a utilização da percepção ambiental é de grande relevância na Educação Ambiental, uma vez que possibilita a compreensão de como os indivíduos investigados percebem o ambiente em que vivem e suas fontes de satisfação e insatisfação com o mesmo. O estudo da percepção permite, ainda, direcionar melhor as estratégias metodológicas de Educação Ambiental que atendam as necessidades de cada localidade (PALMA, 2005).

Nesse sentido, os objetivos deste estudo foram trabalhar o conceito de Unidade de Conservação e sua importância para a conservação da natureza; promover o conhecimento sobre o ecossistema costeiro, a fauna e a flora locais; mostrar os diferentes tipos de degradação ambiental e seus possíveis efeitos na vida humana; e analisar a percepção do público infantil com relação aos temas abordados.

\section{Metodologia}

\section{Área de estudo}

\section{Escolas e Povoados}

As atividades educacionais foram realizadas em duas escolas municipais de Pirambu (SE), localizadas no entorno da Reserva Biológica de Santa Isabel. A Escola Municipal Laudelina Moura Ferreira (EMLMF) possui 201 alunos, distribuídos nos Ensinos Infantil e Fundamental e funciona nos turnos matutino e vespertino. Localiza-se no povoado Aguilhadas, cerca de 4 $\mathrm{km}$ de Pirambu, cuja principal economia são a pesca e a agricultura (TEIXEIRA, 2006; GONZAGA, 2007).

A Escola Municipal Ester Ribeiro Dantas (EMERD) está localizada no povoado Lagoa Redonda, a 19 km de Pirambu, e possui 101 alunos, dentro 
dos Ensinos Infantil e Fundamental e funciona nos turnos matutino e vespertino. O povoado de Lagoa Redonda recebeu esse nome devido a sua geografia, formada por um paredão de areia, que circunda uma área de mangue. Do alto de suas dunas, pode-se avistar o oceano em um dos extremos e o manguezal em outro. Sua economia baseia-se na agricultura, na pesca e no turismo (TEIXEIRA, 2006; GONZAGA, 2007).

\section{Reserva Biológica de Santa Isabel}

A Reserva Biológica de Santa Isabel (REBio) é uma Unidade de Conservação (UC) de proteção integral federal, localizada na porção do Litoral Norte do Estado de Sergipe e abrange áreas dos municípios de Pacatuba e Pirambu. Foi criada pelo Decreto Federal oㅜ 96.999, em 20 de outubro de 1988 e possui uma área total de $2.766 \mathrm{ha}$, sendo $45 \mathrm{~km}$ de praias (ICMBio, 2010; OLIVEIRA; SOUZA, 2011). A REBio é caracterizada, principalmente, por ecossistemas costeiros e possui uma grande diversidade de fauna e flora. A vegetação local é caracterizada por praias associadas a dunas, vegetação de restinga, lagoas permanentes e temporárias, manguezais, estuários e fragmentos de Mata Atlântica. A fauna é caracterizada pela presença de 17 espécies de mamíferos, 86 espécies de aves, 22 espécies de répteis e 28 espécies de anfíbios (BRAGHINI; VILAR, 2013). A REBio é administrada pelo Instituto Chico Mendes de Conservação da Biodiversidade, autarquia ambiental do Governo Brasileiro, vinculada ao Ministério do Meio Ambiente. Sua sede está situada no município de Pirambu, localizado a aproximadamente $30 \mathrm{~km}$ da Capital, Aracaju (Figura1) (ICMBio, 2010).

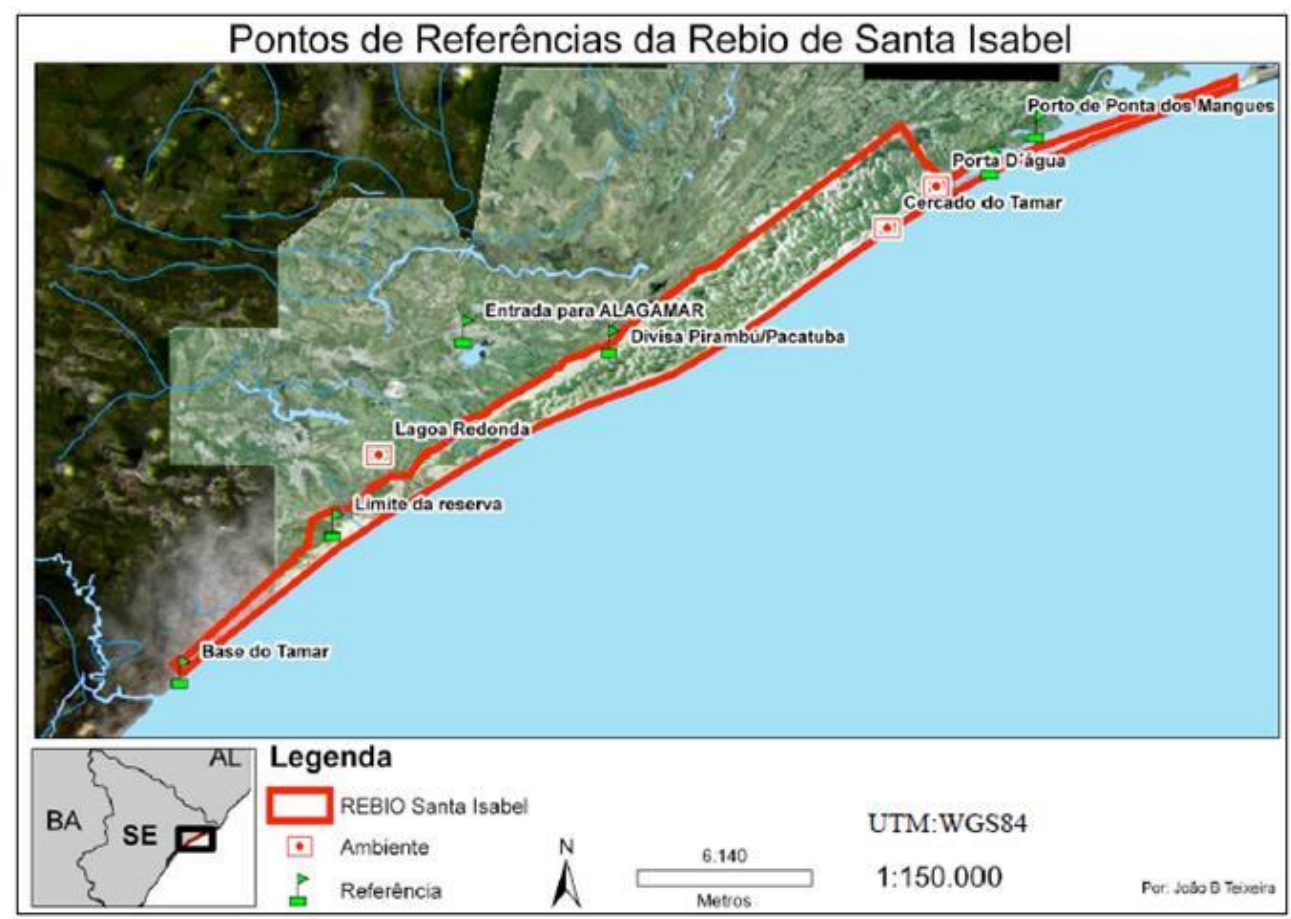

Figura 1: Área da Reserva Biológica de Santa Isabel, Estado de Sergipe. Fonte: Teixeira (2006). 


\section{Descrição das atividades}

Foram realizadas, nas escolas, uma aula de campo, uma palestra, uma apresentação de vídeo e duas atividades educativas. As ações, seus objetivos e procedimentos foram elaborados seguindo estratégicas específicas de Educação Ambiental (DIAS, 2004; 2010; LISBOA; KINDEL, 2012).

A aula de campo teve como intuito apresentar a REBio e mostrar o ecossistema costeiro, com suas características, por meio de uma trilha ecológica, com paradas aleatórias dentro da área da REBio. Em tais paradas, foram contextualizadas a diversidade da fauna e da flora, a poluição por resíduos sólidos e a importância dos recursos hídricos, das dunas, da vegetação de restinga e de sítios arqueológicos encontrados na REBio.

A palestra, com duração de 30 minutos, abordou o conceito de Unidade de Conservação e seus objetivos, mostrando a sua importância para a conservação da natureza, os problemas e ameaças ambientais e a biodiversidade da área e de seu entorno.

O vídeo, com formato de desenho animado "Salve o Planeta", teve duração de $7 \min 19 \mathrm{~s}$ e continha cenas apontando problemas ambientais atuais, como poluição do ar e do mar, desperdício de água, gasto de energia, reciclagem, produção e reutilização de resíduos. O objetivo dessa atividade foi proporcionar uma reflexão para os alunos e discutir a relação dos problemas apresentados no vídeo com aqueles existentes na REBio. A palestra e o vídeo foram apresentados na sala de aula, em ambas as escolas.

Posteriormente, foram realizadas duas atividades práticas, nas quais foi solicitado que cada aluno construísse um desenho a partir das explicações e discussões ocorridas durante a aula de campo, a palestra e o vídeo e, usando massa de modelar, criasse alguma espécie da fauna e/ou flora presente na REBio.

\section{Instrumento de investigação}

A pesquisa foi desenvolvida com uma abordagem metodológica qualitativa, de cunho interpretativo. A coleta de dados foi realizada por meio dos instrumentos de desenho e massa de modelar. Os desenhos confeccionados durante a pesquisa foram analisados de acordo com 0 aparecimento de elementos considerados relevantes na percepção ambiental e esses foram categorizados como positivos ou negativos segundo Barros et al. (2015). Considerou-se como positivas as ilustrações de lugares naturais como áreas de lazer, escolas, parques, matas, jardins ou qualquer desenho que não demonstrasse nenhum tipo de degradação. Como elementos negativos, foram consideradas quaisquer ilustrações envolvendo impactos de degradação, poluição, natureza depredada, dentre outros.

\footnotetext{
${ }^{7}$ Disponível em: <http://www.youtube.com/watch?v=6m7fR3LIntM>
} 


\section{Resultados e discussão}

O público-alvo da pesquisa foram alunos do $6^{\circ}$ ano do Ensino Fundamental II em ambas as escolas, com uma faixa etária entre 11 e 14 anos de idade. Um total de 37 alunos, 21 da Escola Municipal Laudelina Moura Ferreira e 16 da Escola Municipal Ester Ribeiro Dantas foram os participantes das atividades.

A aula de campo proporcionou momentos de descobertas e troca de experiências, permitiu aprofundar os conhecimentos e serviu de incentivo para a sensibilização dos alunos na valorização e conservação do ecossistema costeiro, no qual estão inseridos e onde estão localizadas as suas residências e escola (Figura 2).

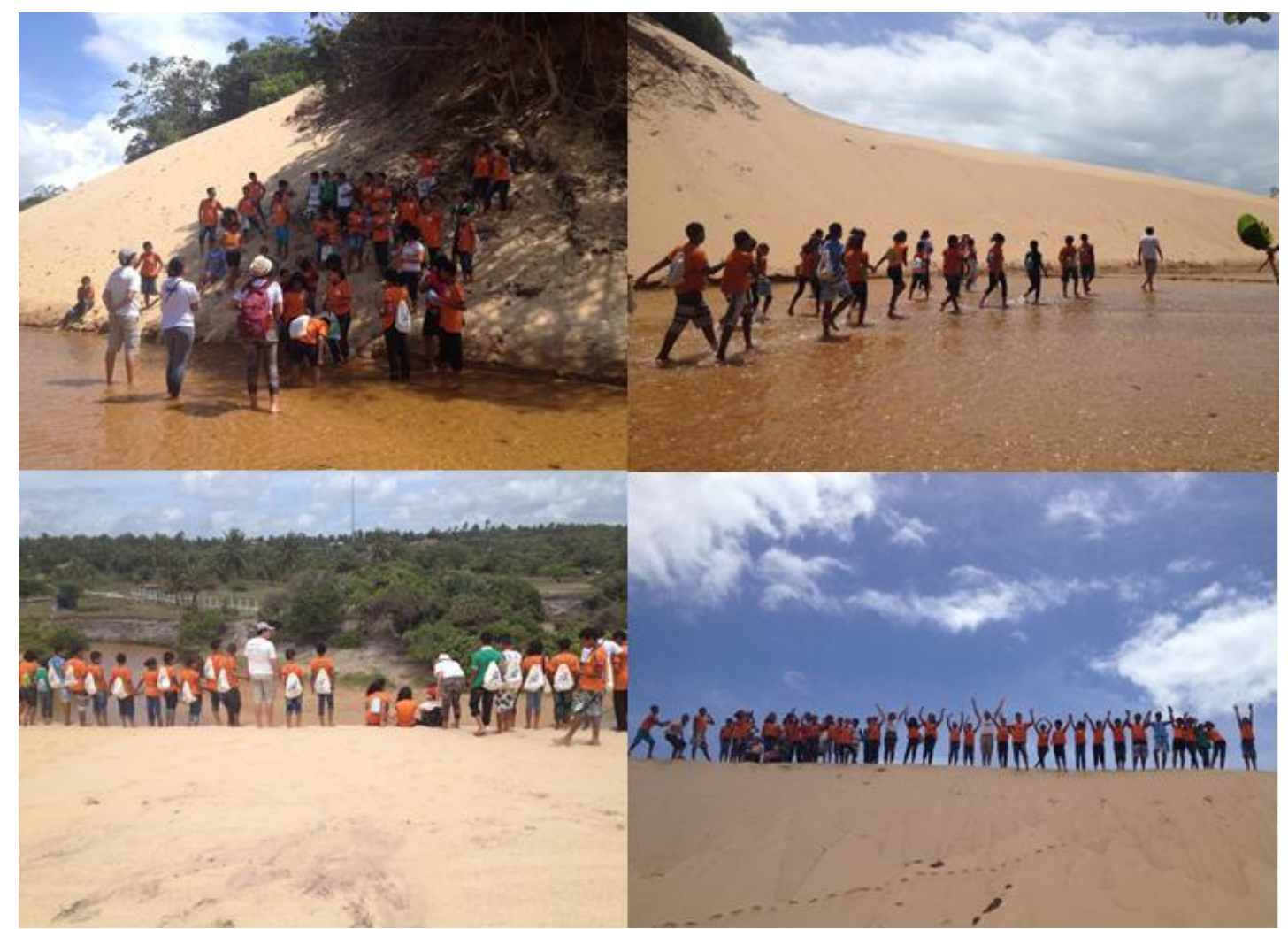

Figura 2: Aula de campo de ambas as escolas, na Lagoa Redonda, Reserva Biológica de Santa Isabel, Pirambu (SE). Fotos: Acervo dos autores. 
Dentro da formação escolar, o treinamento com a atividade de campo é fundamental para a solidificação dos conceitos teóricos, pois permite que o aluno saia das limitações dos livros e da escola, pratique a observação, explore o meio ambiente, contribuindo para despertar a curiosidade e o prazer pelas descobertas de novos saberes, ampliando seus conhecimentos. Essa nova reflexão e aprendizado contribuem para a formação de cidadãos mais conscientes, que conseguem discutir os problemas locais, planejar estratégias e até mesmo implementar medidas práticas para a conservação local, ressaltando a importância de conciliar a educação com o desenvolvimento.

As apresentações de palestra e vídeo são uma forma diversificada de discutir conhecimentos necessários para a formação do cidadão consciente e contribuir para o aperfeiçoamento das atividades extracurriculares. Os alunos foram participativos durante a palestra e o vídeo, interagiram, fizeram perguntas e discutiram informações já conhecidas por alguns, como, por exemplo, a criação de bovinos e caprinos, proibida em unidades de conservação de proteção integral como as reservas biológicas. Por outro lado, os alunos se mostraram bastante surpresos quanto à existência de algumas espécies da fauna silvestre na área da REBio.

Os alunos confeccionaram um total de 43 desenhos, 26 da EMLMF e 17 da EMERD. Quando analisados, 95,4\% dos desenhos (41) foram classificados como negativos ( 25 da EMLMF e 16 da EMERD), porque apresentaram cenas de poluição do ar e/ou do mar, gasto de energia e desperdício de água (Figuras 3 e 4). Somente dois desenhos (4,6\%) foram categorizados como positivos (1 da EMLMF e 1 da EMERD), porque continham cenas de reciclagem.

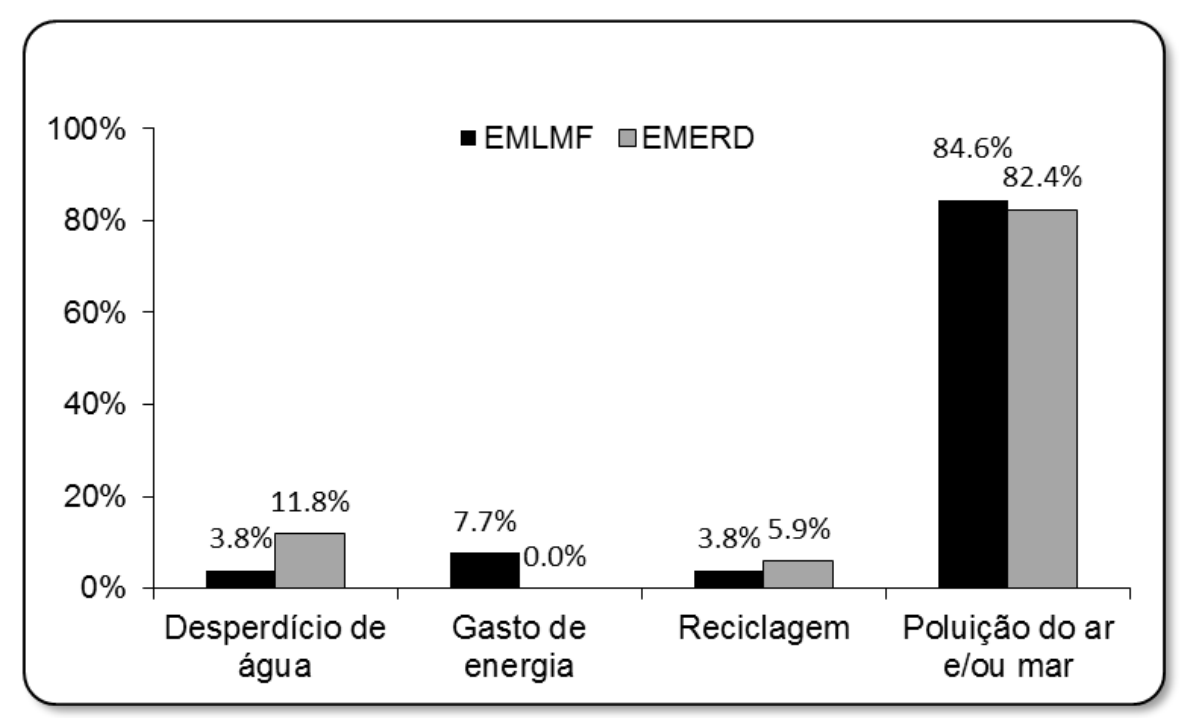

Figura 3: Frequência das ilustrações presentes nos desenhos confeccionadas pelos alunos das Escolas Municipais Laudelina Moura Ferreira e Ester Ribeiro Dantas, Pirambu (SE). 


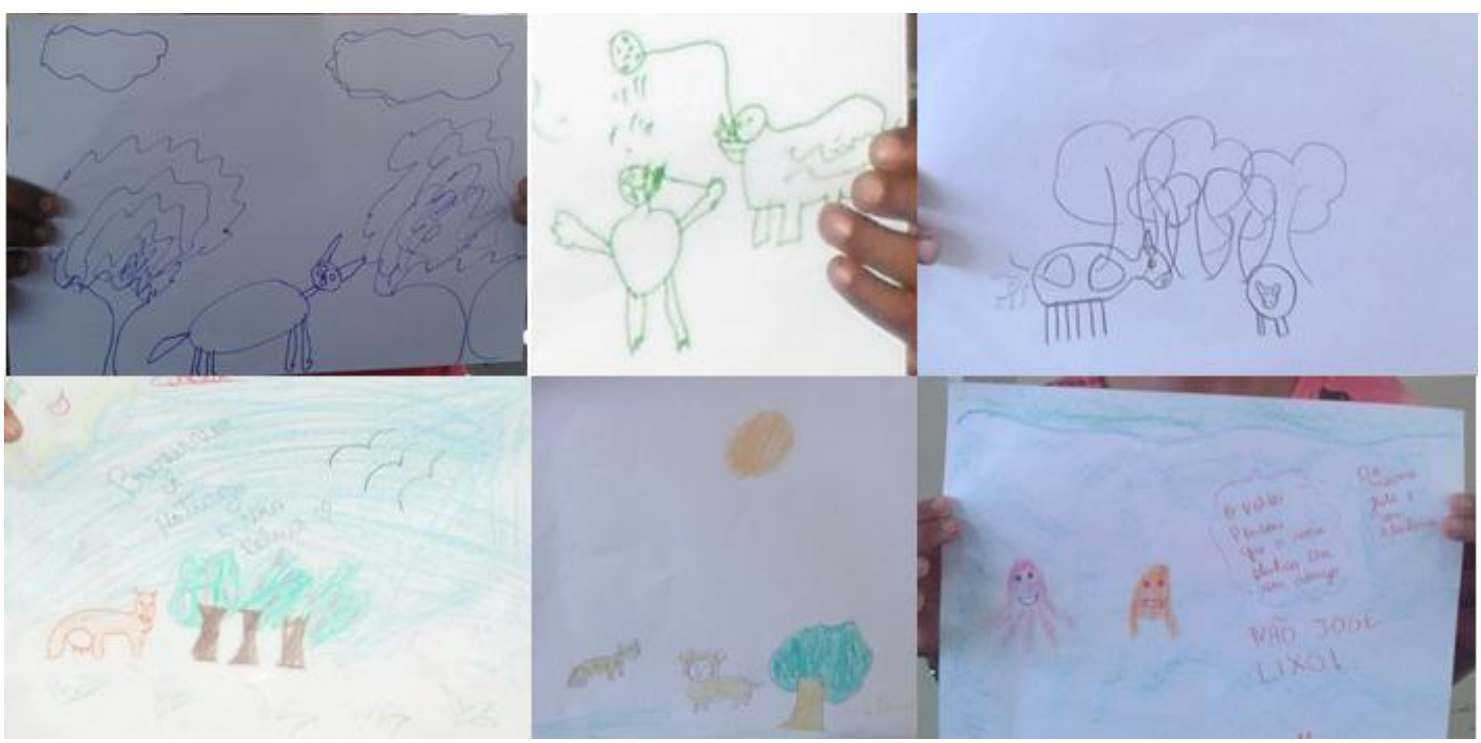

Figura 4: Desenhos confeccionados pelos alunos das Escolas Municipais Laudelina Moura Ferreira e Ester Ribeiro Dantas, para a atividade de percepção ambiental.

Fotos: Acervo dos autores.

Os desenhos mais representativos das duas escolas compreenderam ilustrações de poluição da água (84\%) e do ar (82\%). Essa alta frequência pode demonstrar que os alunos relacionaram os conceitos abordados na palestra e no vídeo com as situações observadas no seu dia-dia, uma vez que a área apresenta diversas fontes de impacto.

Durante a apresentação dos desenhos, os alunos discutiram os problemas que afetam a região e mostraram ter assimilado as informações passadas na aula de campo, na palestra e no vídeo, o que permite inferir que as atividades desenvolvidas, mesmo que em um curto período de tempo, estimularam a visão crítica dos alunos e promoveram uma maior sensibilização sobre o local em que estão inseridos, fortalecendo o vínculo com seu entorno e resultando em uma maior preocupação com a conservação do meio ambiente local.

Os desenhos são uma excelente ferramenta para fornecer informações sobre a percepção ambiental e ecológica e os valores de uma determinada comunidade ou grupo, independente do objetivo do estudo ou do referencial teórico (PILLAR, 1996). Segundo o autor, a representação por meio do desenho é a principal condição para a existência do pensamento, ou seja, não existe pensamento sem representações.

O uso do desenho como instrumento para trabalhar com crianças vem sendo indicado por muitos pesquisadores, que apontam a ferramenta como de fácil aceitação, como recurso relaxante e prazeroso, capaz de ser decodificado e analisado. $O$ desenho pode ser considerado uma imagem próxima do que a criança sente, percebe, conhece acerca do ambiente que habita e atua como 
uma atividade cultural, inteligente e sensível, que interage com diferentes manifestações do comportamento da criança: não-verbais, verbais, visuais e caricaturas que compõem os planos imaginário e real (SCHWARZ; SEVEGNANI; ANDRÉ, 2007; SNADDON, TURNER, FOSTER, 2008).

De acordo com Tuan (1980), o desenho é um sistema de representação, - qual abrange tanto a execução como a interpretação de imagens desenvolvidas por símbolos, usados para expressar fantasias, ideias, sensações e sentimentos. A percepção negativa caracterizada no presente trabalho pode estar relacionada, principalmente, com o que foi observado pelos alunos no campo como a poluição ambiental e o descarte de lixo na praia e no entorno da REBio. Acredita-se que os estudantes conseguiram perceber que a ação antrópica acarreta danos irreversíveis ao meio ambiente, com consequências para a fauna marinha e terrestre e até para os humanos. Possivelmente, eles expressaram cenas cotidianas, indicando que não idealizam ou superestimam o lugar em que vivem.

Utilizando a massa de modelar, foram confeccionados 52 animais e 17 plantas; 23 imagens foram construídas por alunos da EMERD e 46 por alunos da EMLMF (Figuras 5 e 6 ).

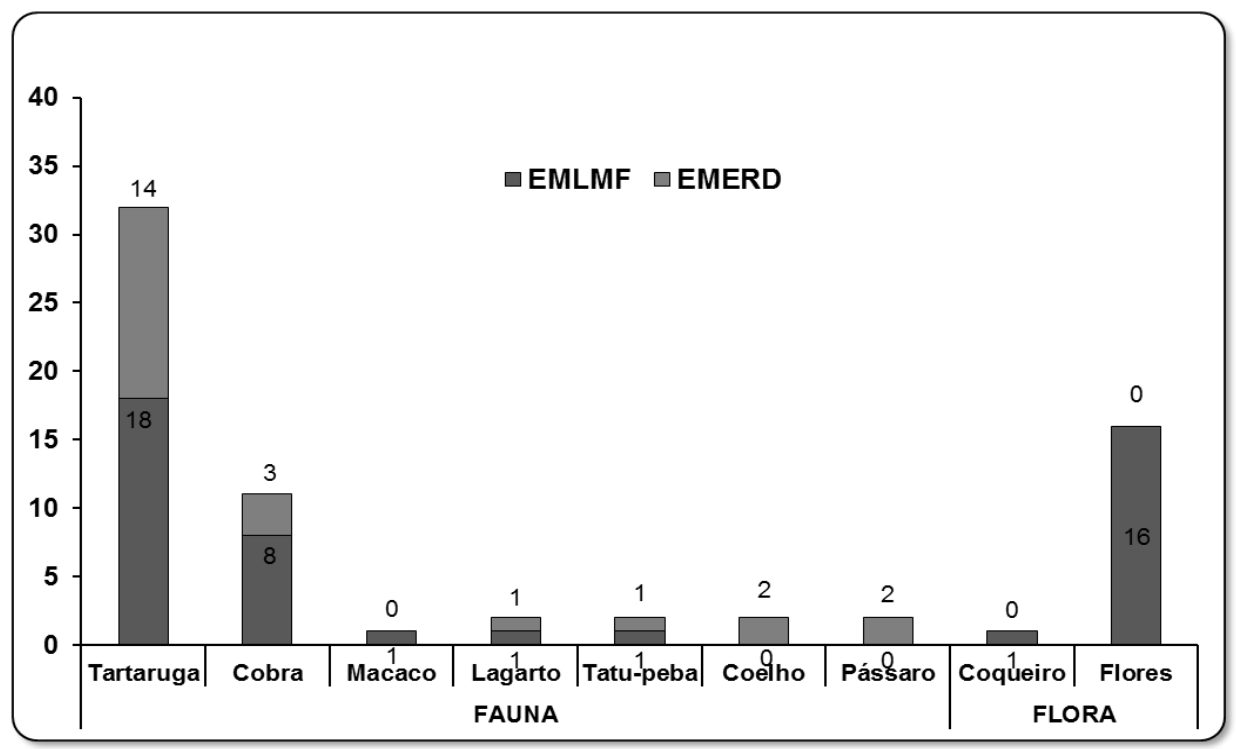

Figura 5: Número de animais e plantas confeccionados com massa de modelar, pelos alunos das Escolas Municipais Laudelina Moura Ferreira e Ester Ribeiro Dantas, Pirambu, (SE). 


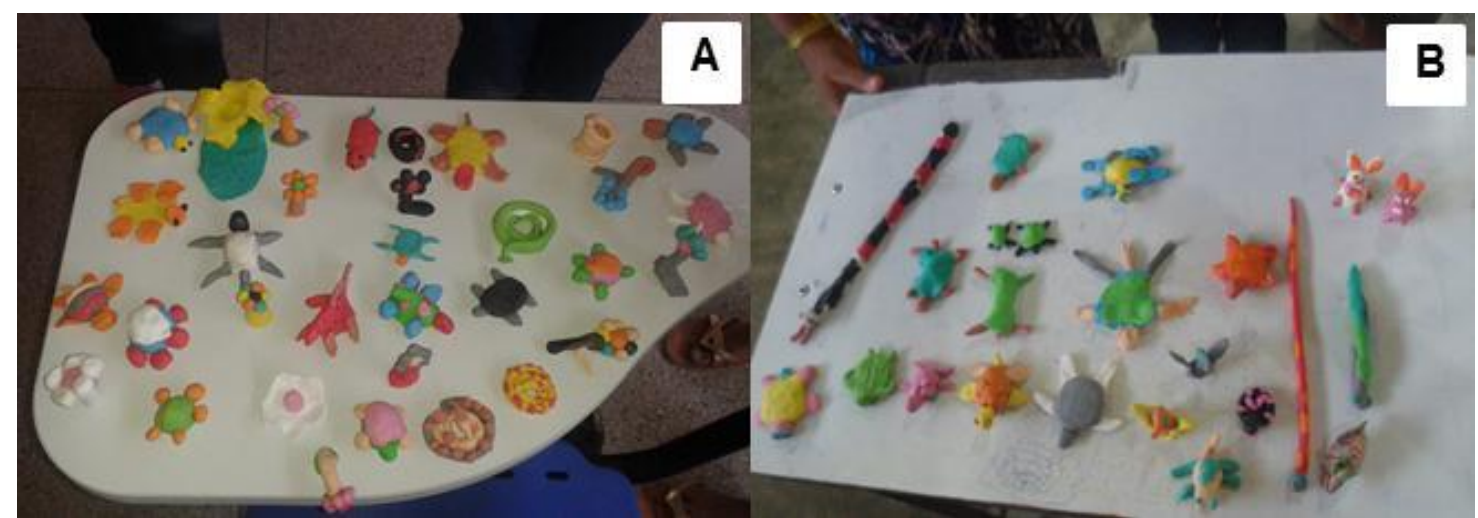

Figura 6: Animais e plantas confeccionados pelos alunos das Escolas Municipais Laudelina Moura Ferreira (A) e Ester Ribeiro Dantas (B). Foto: Acervo dos autores.

Destaca-se que, em ambas as escolas, foram confeccionadas espécies de diferentes grupos de vertebrados, abrangendo répteis, aves e mamíferos. Porém, em ambas as escolas, foi confeccionado um maior número de tartarugas marinhas (18 na EMERD e 14 na EMLMF), o que pode ter relação com a presença desse grupo na área estudada. Todo o litoral de Pirambu é uma das principais áreas de desova de diversas espécies de tartarugas marinhas no estado de Sergipe e, todo ano, muitos animais saem para desovar nas praias da região. Além disso, a proteção da fauna local e das áreas de desovas de tartarugas marinhas é um dos principais objetivos de criação da REBio. Adicionalmente, durante anos, o local abrigou um centro de visitantes do Projeto TAMAR e todos esses fatores podem ter influenciado a grande representação desse grupo nos modelos construídos.

Por outro lado, apesar de ambas as escolas estarem próximas da REBio de Santa Isabel e terem contato direto com a vegetação, somente os alunos da EMLMF confeccionaram elementos da flora local, que foram um coqueiro e 16 flores. Pedrini, Costa e Ghilardi (2010) relatam que há maior percepção por parte das crianças e pré-adolescentes dos aspectos da atmosfera e da fauna terrestre do que da flora, que é bem mais rica em variedade que ambas, demonstrando que os vegetais são pouco percebidos pelos estudantes. Já Schwarz, Sevegnani e André (2007) acreditam que as crianças têm dificuldade de expressar a vegetação, com sua biodiversidade, devido a sua falta de habilidades ao desenhar, sobretudo com o passar da idade.

Diversos autores ressaltam a predominância dos desenhos de flores em relação às outras partes de uma planta e discutem sua relação com o apelo estético, o aroma e o fato de diversas localidades (instituições de ensino, casas), mesmo em áreas urbanas, serem cercadas de jardins, o que traz um impacto visual nas crianças (MARTINHO; TALAMONI, 2007; PEDRINI; DEPAULA, 2008). As representações podem ser consideradas como 
conhecimento cotidiano e prática do saber na experiência vivenciada por esses atores (JODELET, 2002).

Os resultados obtidos com as ilustrações dos desenhos e com a massa de modelar evidenciam a necessidade de mais projetos com intuito de informar e sensibilizar os alunos, pois se nota que a maioria dos estudantes não possui conhecimento sobre importantes conceitos ambientais, conservação da fauna e flora e importância de uma Unidade de Conservação como a Reserva Biológica de Santa Isabel.

Salvarani, Fernandes e Morgano (2013) observaram a falta de conhecimentos sobre tartarugas marinhas durante um diagnóstico da percepção de alunos, em duas escolas, em Aveiro, Portugal. Segundo os autores, isso se relaciona com a necessidade de existir nas escolas projetos que sensibilizem os discentes quanto às questões relacionadas com a conservação do ambiente, principalmente com as espécies em perigo de extinção. No presente estudo, apesar de os alunos terem representado as tartarugas marinhas na maioria dos modelos de massa de modelar, não se pode afirmar que os mesmos têm conhecimento sobre as espécies e suas características, mas que elas são, pelo menos, percebidas.

Todos os animais desenhados ou confeccionados com massa de modelar pelos alunos de ambas as instituições fazem parte da fauna brasileira e da localidade. Schwarz, Sevegnani e André (2007), em seu estudo sobre representações da Mata Atlântica e de sua biodiversidade por meio dos desenhos infantis, encontraram ilustrações de espécies exóticas como leão, urso e elefante. Os autores sugerem que existe influência da mídia, que, por meio de filmes, desenhos animados, documentários e programas de TV, interfere na apresentação desses animais, uma vez que os alunos desse estudo eram provenientes de instituições particulares, pertencentes às classes média e alta.

Desse modo, pode-se salientar que as atividades práticas desenvolvidas dentro da escola, por meio da Educação Ambiental, estimulam trabalhos interdisciplinares de divulgação e discussão dos problemas ambientais, além de contribuir para a formação de alunos mais críticos e comprometidos com a conservação ambiental, para enfrentar os problemas atuais e tomar decisões plausíveis, para transformar suas comunidades, promovendo 0 desenvolvimento local e regional (BERLINCK et al., 2003; CASTRO, 2009; BENACHIO; COLESANTI, 2011). Logo, a escola tem papel fundamental na construção desse cidadão e no fortalecimento da cidadania, com finalidade de tornar a comunidade mais responsável, buscando como consequência um ambiente mais saudável para todos (NAGAGATA, 2006). 


\section{Conclusão}

A percepção com desenhos e massa de modelar aponta que os alunos de duas escolas de Pirambu (SE) têm um breve conhecimento sobre a Reserva Biológica de Santa Isabel, principalmente com relação à fauna e aos impactos no ambiente marinho. A espécie mais representada foi a das tartarugas marinhas. Além disso, foi percebido, nos desenhos, que os estudantes percebem seu ambiente de forma negativa, influenciados pela poluição e pela degradação local, porém apresentam certa afetividade pelo local. Os alunos mostraram ter assimilado as informações passadas na aula de campo, na palestra e no vídeo, por meio das ilustrações nos desenhos e na massa de modelar. Isso permite inferir que as atividades desenvolvidas reforçaram o interesse e a descoberta e estimularam a visão crítica dos alunos, aproximando-os da realidade dos temas abordados e promovendo uma maior sensibilização sobre o local onde eles estão inseridos, o que fortalece o seu vínculo com o entorno e resulta em uma maior preocupação com a conservação do meio ambiente local.

Nesse contexto, a pesquisa sobre percepção ambiental, associada à Educação Ambiental, apresentam uma abordagem relativamente nova, por meio da qual é possível conhecer o público envolvido, partindo da realidade do grupo em estudo. Esse enfoque é importante para o fortalecimento de ações locais, capazes de agregar benefícios ao ambiente e proporcionar uma relação sustentável entre as comunidades e o meio ambiente, contribuindo, de maneira direta, para uma gestão socioambiental participativa e para o desenvolvimento local.

Desse modo, as atividades desenvolvidas foram de suma importância para a interação dos alunos com a Reserva Biológica de Santa Isabel e para o aprendizado dos mesmos, trabalhando conceitos de forma lúdica, prática e dinâmica e utilizando a Educação Ambiental como ferramenta para propagar informações ambientais dentro da escola. Contudo, percebe-se que novas propostas, com maior periodicidade, são importantes para fortalecer 0 envolvimento da escola, incluindo outras séries, novas vivências e trocas de experiências.

\section{Agradecimentos}

À Universidade Tiradentes, Curso de Graduação em Ciências Biológicas e Laboratório de Biologia Tropical do Instituto de Tecnologia e Pesquisa; ao ICMBio e à equipe da Reserva Biológica de Santa Isabel; aos Gestores da REBio, Paulo Jardel Braz Faiad e Luciana Viana Faiad; ao Secretário de Educação de Pirambu, Sr. José Luis de Andrade; aos diretores das Escolas Municipais Laudelina Moura Ferreira e Ester Ribeiro Dantas, Maria Aparecida e Paulo Sérgio, respectivamente, e aos professores das escolas, pela confiança e colaboração na realização das atividades; e, finalmente, aos alunos do $6^{\circ}$ ano do Ensino Fundamental II, por participarem das atividades, e aos seus pais, pela autorização da participação. 


\section{Referências}

BARROS, M.M.; TAVARES, G.G.; PEIXOTO, J.C.; SILVA, S.D. Vivenciar e perceber o lugar. Estudo da percepção ambiental de escolares da rede municipal de ensino da cidade de Anápolis, Goiás, Brasil. Investigação Qualitativa em Educação, v. 2, p. 414-420, 2015.

BENACHIO, M.V.; COLESANTI, M.T.M. Educação Ambiental \& elementos para uma escola pública participativa. Revista Geográfica de América Central, Costa Rica II, Número Especial EGAL, p. 1-12, 2011.

BERLINCK, C.N.; CALDAS, A.L.R.; MONTEIRO, A.H.R.R.; SAITO, C.H. Contribuição da Educação Ambiental na explicitação e resolução de conflitos em torno dos recursos hídricos. Ambiente e Educação, Rio Grande, v. 8, p. 117-129, 2003.

BEZERRA, T.M.O.; FELICIANO, A.L.P.; ALVES, A.G.C. Percepção ambiental de alunos e professores do entorno da estação ecológica de Caetés - região metropolitana do Recife - PE. Revista Biotemas, v. 21, n. 1, p. 147-160, 2008.

BOSSCHE, J.V. Dessine-moi ton monde: l'art enfantin dans plusieurs parties du monde. Bélgica: Mardaga, 2006.

BRAGHINI, C.R.; VILAR, J.W. C. Gestão territorial de áreas protegidas no litoral sergipano: primeiras incursões. Ambivalências - Revista do Grupo de Pesquisa "Processos Identitários e Poder", v. 1, n. 1, 2013.

CASTRO, R.S. A construção de conceitos científicos em Educação Ambiental. In: LOUREIRO, C.F.B.; LAYRARGUES, P.P.; CASTRO, R.S.; BARBOSA, G.L.; QUINTAS, J.S.; ZBOROWSKI, M.B.; ZACARIAS, R.; MOLON, S.I. Repensar a Educação Ambiental: um olhar crítico. São Paulo: Cortez, 2009. p. 173-202.

CHAWLA, L. Spots of time: manifold ways of being in nature in childhood. In: KAHN, P. H. J.; KELLERT, S. R. (Orgs.). Children and nature: psychological, sociocultural and evolutionary investigation. Cambridge: Massachusetts Institute of Technology Press, 2002. p. 199-225.

DIAS, G.F. Educação Ambiental: princípios e práticas. São Paulo: Gaia, 2004.

DIAS, G.F. Dinâmicas e instrumentação para Educação Ambiental. São Paulo: Gaia, 2010.

DERDYK, E. Formas de pensar o desenho: o desenvolvimento do grafismo infantil. Porto Alegre: Zouk, 2010.

GONZAGA, T.P.A. Povoados do munícipio de Pirambu - SE: Necessidade da população local de olhar o lugar. Revista eletrônica - Atêlie geográfico, Goiânia - GO, v. 1, n. 2, p. 210-217, 2007.

ICMBio. Proposta de retificação e atualização dos limites da Reserva Biológica de Santa Isabel, no Estado de Sergipe. Relatório Técnico, 2010.

JODELET, D. Representações sociais: um domínio em expansão. Rio de Janeiro: EdUERJ, 2002.

revista brasileira educação ambiental 
KAHN, P.H.J. Children's affiliations with nature: structure, development and the problem of environmental generational amnesia. Cambridge: Massachusetts Institute of Technology Press, 2002.

LISBOA, C.P., KINDEL, E.A.I. Educação Ambiental: da teoria à prática. Porto Alegre: Mediação, 2012.

MARCATTO, C. Educação Ambiental: conceitos e princípios. Belo Horizonte, FEAM, 2007.

MARIN, A.A. Pesquisa em Educação Ambiental e percepção ambiental. Pesquisa em Educação Ambiental, Ribeirão Preto, v. 3, n. 2, p. 203-222, jun. 2008.

MARTINHO, L.R.; TALAMONI, J.L.B. Representações sobre meio ambiente de alunos da quarta série do ensino fundamental. Ciência \& Educação, Bauru, v. 13, n. 1, p. 1-13, 2007.

NAGAGATA, E. A importância da Educação Ambiental como ferramenta adicional a programas de conservação. In: ROCHA, C.F.D.; BERGALLO, H.G.; SLUYS, M.V.; ALVES, M.A.S. (Eds.) Biologia da conservação, essências. São Carlos, SP: RiMa Editora, 2006. p. 53-90.

OLIVEIRA, A.C.C.A.; SOUZA, R.M. Ecodinâmica dos sistemas dunares do município de Pirambu, Litoral Norte de Sergipe. Sociedade e Território, v. 23, n. 2, p. 2-20, 2011.

PALMA, I.R. Análise da percepção ambiental como instrumento ao planejamento da Educação Ambiental. Dissertação (Mestrado em Engenharia) - Escola de Engenharia, Universidade Federal do Rio Grande do Sul, 2005.

PEDRINI, A.G.; DE-PAULA, J.C. Educação Ambiental: críticas e propostas. In: PEDRINI, A.G. (Org.). Educação Ambiental: reflexões e práticas contemporâneas. Petrópolis: Vozes, 2008. p. 90-146.

PEDRINI, A.G.; COSTA, E.A.; GHILARDI, N. Percepção ambiental de crianças e pré-adolescentes em vulnerabilidade social para projetos de Educação Ambiental. Ciência \& Educação, v. 16, n. 1, p. 163-179, 2010.

PILLAR, A.D. Desenho e construção de conhecimento na criança. Porto Alegre: Artes Médicas, 1996.

SALVARANI, P.I.; FERNANDES, A.C.M.; MORGANO, F.M.R. Percepção ambiental de estudantes na conservação das tartarugas marinhas em Aveiro, Portugal. Revista da Gestão Costeira Integrada, v. 13, n. 2, p. 137-144, 2013.

SANTOS, M.C.; FLORES, M.D.; ZANIN, E.M. Trilhas interpretativas como instrumento de interpretação, sensibilização e Educação Ambiental na APAE de Erechim/RS. Vivências, v. 7, n. 13, p. 189-197, 2011.

SCHWARZ, M.L.; SEVEGNANI, L.; ANDRÉ, P. Representações da mata atlântica e de sua biodiversidade por meio dos desenhos infantis. Ciência \& Educação, v. 13, n. 3, p. 369-388, 2007. 
SINNER, A. Landscapes of meaning: from childhood art to geographies of self as artist/researcher/teacher. Canadian Journal of Education, v. 31, n. 11, p. 255-262, 2008.

SNADDON, J.L.; TURNER, E.C.; FOSTER, W. A. Children's perceptions of rainforest biodiversity: which animals have the lion's share of environmental awareness? PlosOne, n. 3, v. 7, p. 1-5, 2008.

TEXEIRA, J.B. AER - Avaliação Ecológica Rápida Reserva Biológica de Santa Isabel - SE. Relatório técnico. Vitória, Março, 2006. Disponível em: $<$ http://issuu.com/vozdanatureza/docs/name889ac4>. Acesso em: 12 ago. 2015.

TUAN, I.F. Children and the natural environment. Nova York: Plenum, 1978.

TUAN, I.F. Topofilia: um estudo da percepção, atitudes e valores do meio ambiente. São Paulo: DIFEL, 1980. 